Konstanzer Online-Publikations-System (KOPS)

URL: http://www.ub.uni-konstanz.de/kops/volltexte/2007/4231/

URN: http://nbn-resolving.de/urn:nbn:de:bsz:352-opus-42314

\section{Changed perceptions in Braille readers}

The mature mammalian nervous system has a striking capacity for plastic remodelling in response to environmental changes, but little is known about the perceptual and behavioural relevance of this phenomenon. Using magnetic source imaging we show that the cortical somatosensory representation of the fingers is topographically disordered in blind Braille readers who use three fingers on both hands to read. In addition, they frequently misperceive which of these fingers is being touched. This correlation is suggestive of a functional role for cortical reorganization in the perceptual experience of these individuals.

The somatosensory cortical representation of fingers expands when the amount of sensory input arriving in that part of the brain is increased ${ }^{1-6}$. Indeed, we have previously used magnetic source imaging to show that the somatosensory cortical representation of the left hand of string players, which engages in the complex and demanding task of fingering the strings, is expanded ${ }^{1}$. To test the hypothesis that fusion of cortical representations is caused by increased simultaneous stimulation ${ }^{7-9}$, we tested the somatotopic representations of four blind Braille readers who used three fingers (digits 2-4) of both hands simultaneously for reading, and were instructors of the method typically engaged in this practice for several hours a day. We also tested six Braille readers who employed one finger for reading, and five sighted non-Braillereading subjects. Magnetic source imaging was used to determine the centre of cortical magnetic responsivity to light tactile stimulation of the finger tips (left and right D1, D2 and D5) and right and left lower lip .

There was a substantial enlargement of the hand representation in the three-finger Braille readers compared with the other two groups (three-finger readers, $14 \mathrm{~mm}$; one-finger readers, $8 \mathrm{~mm}$; sighted, $7 \mathrm{~mm}$; $\left.F_{2,12}=16.6, \quad P<0.001\right)$. The three-finger readers also differed from sighted subjects in the topographical arrangements of the finger representations along the postcentral gyrus (Fig. 1). In all sighted subjects the expected homuncular pattern was observed; D1 being inferior (lateral), D2 being more medial, and D5 being the most superior (medial). In each of the three-finger Braille readers, this pattern was changed in one or both hemispheres. Only one of the one-finger Braille readers' cortical topography of finger representations was disordered. These are significant differences $(P<0.005$, Fisher's exact test, 2 -tailed $)$,

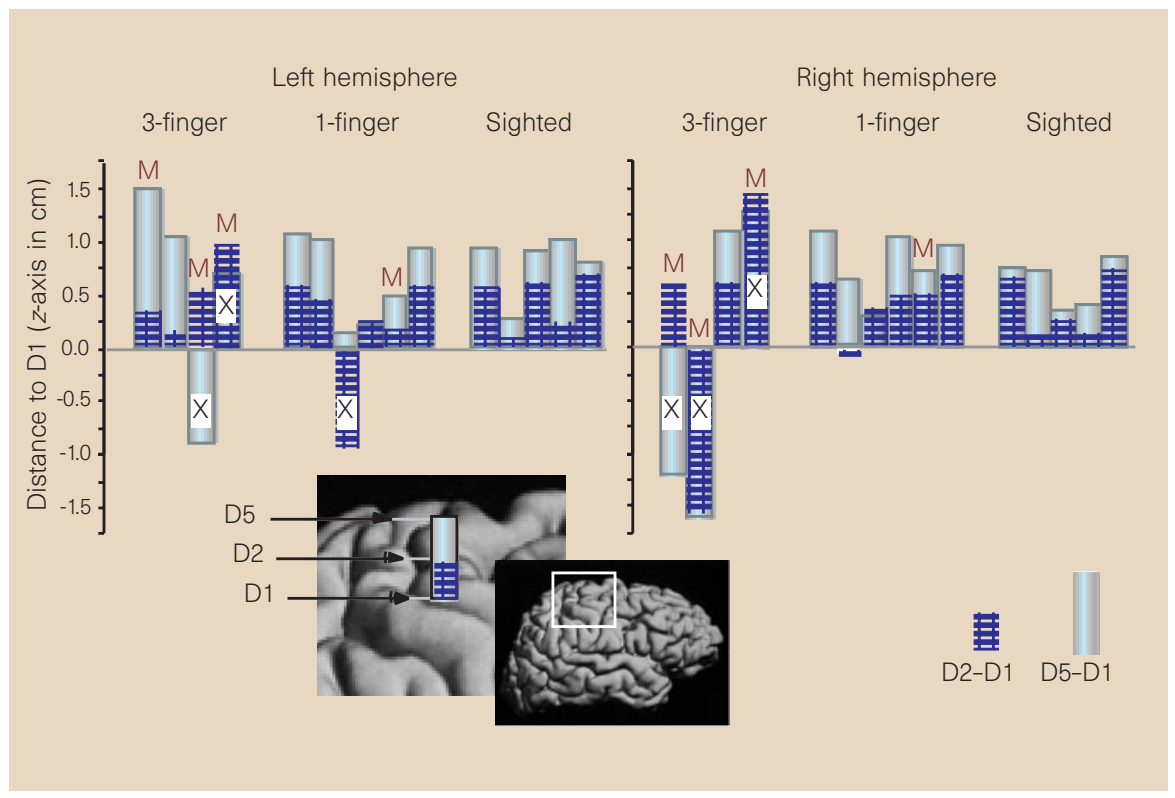

Figure 1 Distances between centres of cortical responsivity: D1, thumb; D2, index finger; D5, little finger. Distances are displayed with reference to the D1 location, which is graphed at the zero-line. The inset shows the centre of responsivity for D1, D2 and D5 superimposed on the brain of a sighted subject. X, Hemispheres in which the homuncular organization of the cortical representations of the fingers was disordered; $\mathrm{M}$, cortical representation of hands in which the location of tactile stimulation was mislocalized. 
with the three-finger readers differing significantly from the one-finger readers $(P<0.02)$ and sighted controls $(P<0.008)$, whereas the latter groups were not significantly different from one another.

Each of the three-finger readers had a strong tendency to misidentify which finger was being touched during tactile sensory threshold determination, although there was no difficulty in determining that one of the fingers had been touched. In contrast, none of the sighted subjects and only one of the one-finger readers reported such difficulties. Again these are significant differences (for the three groups, $P<0.005$; three-finger against one-finger, $P<0.02$; three-finger against sighted, $P<0.008$; Fisher's exact test, 2-tailed). Sensory threshold testing was also conducted in five other sighted individuals, none of whom had difficulty in localizing tactile stimuli.

A striking feature of the data was the coincidence between the digital topographic disorder in the cerebral cortex and the mislocalization of tactile stimulation of the fingers. This relationship was significant when the data from all individuals were pooled (Fisher's exact test, $P=0.017$ ). For the three-finger Braille readers, the hand opposite each of the hemispheres in which there was disorder exhibited a corresponding tactile mislocalization.

'Smearing' of the digital cortical representation could be adaptive for Braille readers who use three fingers in that it serves to fuse input transmitted over different fingers, so that the incoming information can be processed as a whole. Thus, use-dependent cortical reorganization can be associated with functionally relevant changes in the perceptual capacity of the individual.

Annette Sterr, Matthias M. Müller, Thomas Elbert, Brigitte Rockstroh Department of Psychology, University of Konstanz, Fach D25, D-78457 Konstanz, Germany

\section{Christo Pantev}

Institute of Experimental Audiology,

University of Münster, D-48129 Münster, Germany

\section{Edward Taub}

Department of Psychology,

University of Alabama at Birmingham,

Birmingham, Alabama 35294, USA

1. Elbert, T., Pantev, C., Wienbruch, C., Rockstroh, B. \& Taub, E. Science 220, 21-23 (1995).

2. Elbert, T., Sterr, A., Flor, H., Rockstroh, B., Knecht, S. \& Taub, E. Exp. Brain Res. 117, 161-164 (1997).

3. Recanzone, G. H., Jenkins, W. M. \& Merzenich, M. M. J. Neurophysiol. 67, 1015-1030 (1992).

4. Recanzone, G. H., Merzenich, M. M. \& Jenkins, W. M. J. Neurophysiol. 67, 1057-1070 (1992).

5. Recanzone, G. H., Merzenich, M. M., Jenkins, W. M., Grajski, A. \& Dinse, H. R. J. Neurophysiol. 67, 1031-1056 (1992).

6. Jenkins, W. M., Merzenich, M. M., Ochs, M. T., Allard, T. \& Guíc-Robles, E. J. Neurophysiol. 63, 82-104 (1990).

7. Allard, T., Clark, S. A., Jenkins, W. M. \& Merzenich, M. M. J. Neurophysiol. 66, 1048-1058 (1991).

8. Wang, X., Merzenich, M. M., Sameshima, K. \& Jenkins, W. M. Nature 378, 71-75 (1995)

9. Byl, N. N., Merzenich, M. M. \& Jenkins, W. M. Neurology 47, 508-520 (1996). 